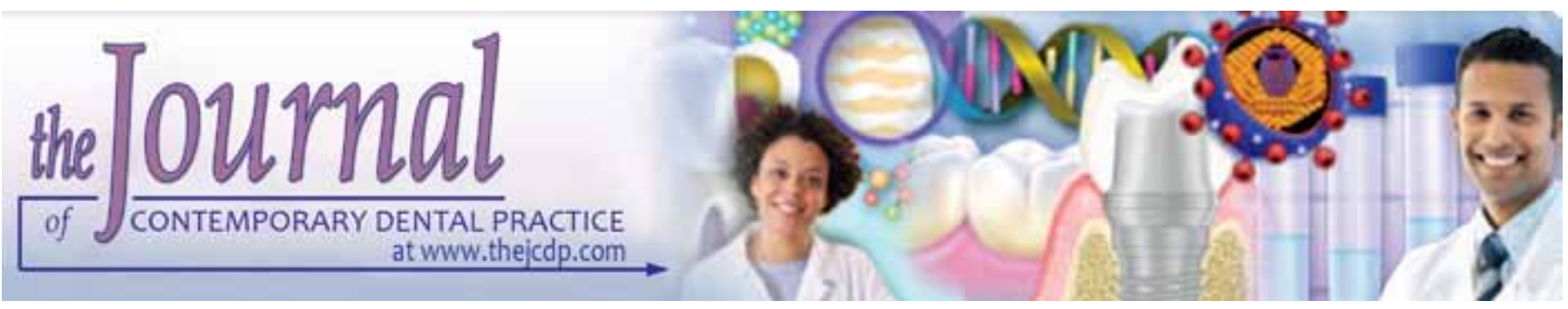

\title{
Alpha-2-Macroglobulin Levels in Gingival Crevicular Fluid Pre- and Post-scaling and Root Planing with Adjunctive Tetracycline Fibers in Chronic Periodontitis: A Randomized Controlled Trial
}

\author{
${ }^{1}$ Shivjot Chhina, ${ }^{2}$ Ajit Singh Rathore, ${ }^{3}$ Saurabh Juneja
}

\begin{abstract}
Background: This split-mouth clinical study aimed to investigate levels of alpha-2-macroglobulin ( $\alpha 2 M)$ in gingival crevicular fluid (GCF) of chronic periodontitis patients pre- and post-scaling and root planing (SRP) with or without adjunctive use of tetracycline fibers.
\end{abstract}

Materials and methods: In 30 patients of chronic periodontitis, samples of GCF were collected from the gingival sulcus before SRP. Recording of clinical parameters was conducted. This was followed by local drug delivery (LDD) of tetracycline fibers in test sites. In control sites, no LDD was done. Second samples of GCF were taken 90 days after treatment. Samples of crevicular fluid were analyzed to determine the levels of $\alpha 2 \mathrm{~m}$.

Results: A gain of clinical attachment (CAL) of $3.30 \mathrm{~mm}$ for SRP and LDD and for SRP alone was $1.62 \mathrm{~mm}(p<0.001)$. The pocket probing depth was significantly decreased by $2.43 \mathrm{~mm}$ for SRP and LDD and for SRP alone was $1.61 \mathrm{~mm}(p<0.001)$ after 90 days. Alpha-2-macroglobulin was significantly reduced in GCF by SRP and SRP and LDD after 90 days ( $p<0.001)$.

Conclusion: Clinical and biochemical variables showed a more favorable outcome when SRP was combined with LDD of tetracycline fibers in management of patients suffering from chronic periodontitis.

Keywords: Alpha-2-macroglobulin, Chronic periodontitis, Gingival crevicular fluid, Local drug delivery, Tetracycline.

How to cite this article: Chhina S, Rathore AS, Juneja S. Alpha-2-Macroglobulin Levels in Gingival Crevicular Fluid

${ }^{1}$ Department of Periodontics, ITS Dental College, Hospital and Research Centre, Greater Noida, Uttar Pradesh, India

2,3 Department of Oral and Maxillofacial Pathology, ITS Dental College, Muradnagar, Ghaziabad, Uttar Pradesh, India

Corresponding Author: Shivjot Chhina, Professor, Department of Periodontics, ITS Dental College, Hospital and Research Centre, Greater Noida, Uttar Pradesh, India, Phone: 01204228389, e-mail: drshivjot74@gmail.com
Pre- and Post-scaling and Root Planing with Adjunctive Tetracycline Fibers in Chronic Periodontitis: A Randomized Controlled Trial. J Contemp Dent Pract 2015;16(6):474-478.

Source of support: Nil

Conflict of interest: None

\section{INTRODUCTION}

Periodontal diseases pose as significant public health issues, as they are among the most prevalent human diseases. ${ }^{1}$ The persistence of assembly of bacteria along with proinflammatory destructive events in the periodontal tissues are associated with disease and if left unchecked in tooth mortality. Much of the destruction associated with periodontal disease can be attributed to an ebullient inflammatory response.

The challenge of bacterial bio burden results in the innate defensive system activation by means of gingival crevicular fluid (GCF), saliva and oral epithelium. Gingival crevicular fluid contains a wide array of biologically active molecules, many of which correlate positively with the severity of periodontal diseases. For this reason, it offers a promise in providing information about early disease progression and insight into the host response. ${ }^{2}$

A major component of GCF, are the antimicrobial proteins (AMPs). Antimicrobial proteins have an ability to inactivate bacteria, fungi, protozoa and few enveloped viruses, they, thus, protect the oral tissues from infection. ${ }^{3}$

In healthy periodontal tissues, a balance exists between proteinases and their inhibitors. Proteases, such as collagenases, elastases, and cathepsins have been implicated in tissue destruction. ${ }^{4,5}$

Alpha-1-antitrypsin and alpha-2-macroglobulin ( $\alpha 2 \mathrm{M})$ are among the major serum proteinase inhibitors, which 
can be isolated from the GCF also. The specific inhibitor of leukocyte elastase, chymotrypsin, trypsin, is alpha-1antitrypsin, contrastingly $\alpha 2 \mathrm{M}$ acts as a broad-spectrum inhibitor to a myriad of host and bacterial proteases. ${ }^{6}$

Increased levels of antimicrobial plasma protein, $\alpha 2 \mathrm{M}$ are elicited in GCF due to increased vascular permeability during inflammation. It is synthesized by gingival fibroblasts and macrophages present in the tissues and the gingival crevice. ${ }^{7}$

Alpha-2-macroglobulin is a major regulator of collagenolysis due to its ability to rapidly bind to MMP-1, thereby regulating MMP activity in body fluids. ${ }^{8}$ Alpha2-macroglobulin acts as an inhibitor of fibrinolysis by downregulating plasmin and kallikrein. It also mediates inhibition and removal of proteolytically harmful endoproteases. $^{9}$

Schenkein and Genco are credited with isolation of $\alpha 2 \mathrm{M}$ from the gingival crevice of diseased sites and delineated their concentration to be about $70 \%$ of those found in serum. ${ }^{10}$

Alpha-2-macroglobulin exists in two different forms in vivo, i.e. total and transformed form. ${ }^{11}$ Host derived or bacteria impelled, increase in protease, may show a reaction with $\alpha 2 \mathrm{M}$, thus, increasing the transformed $\alpha 2 \mathrm{M}$ (fraction of $\alpha 2 \mathrm{M}$ proteinase complex). Resolution of inflammation has been found to be associated with decreasing absolute values of $\alpha 2 \mathrm{M}$ in GCF samples, ${ }^{12,13}$ thereby underlying its potential to be used for estimation of presence of inflammation.

The major source of $\alpha 2 \mathrm{M}$ in GCF is the serum, its local synthesis by gingival cells occurs during inflammation. ${ }^{14,15}$ Presence of large quantities of $\alpha 2 \mathrm{M}$ in GCF is an indicator of vascular leakage in the gingival crevice. ${ }^{16}$

Standard treatment protocols for addressing periodontal disease include mechanical removal of plaque and calculus, thereby physically disrupting the subgingival biofilm, and thus bringing down the burden of inflammation. Adjunctive therapies to mechanical debridement, such as local drug delivery (LDD) have shown promising results in management of chronic periodontitis.

The present split mouth study aims to analyze: (1) The effect of scaling and root planing and LDD of tetracycline fibers on the quantitative values of $\alpha 2 \mathrm{M}$ (subgingival biofilm 2m) in GCF of chronic periodontitis patients, (2) effect of these different therapeutic modalities on clinical parameters and (3) to investigate the plausible relation between clinical and biochemical variables.

\section{MATERIALS AND METHODS}

A total of 30 patients, (15 males and 15 females) with a mean age of 44.8 years, diagnosed with chronic periodontitis were enrolled in the study with no dropout. An informed written consent was obtained from all participants.

\section{Inclusion Criteria}

- Subjects of both genders, in the age group of 30 to 65 years.

- Subjects having at least 20 scorable natural teeth in their mouth.

- Chronic periodontitis ${ }^{17}$ patient $\geq 6$ natural teeth, with pocket probing depth (PPD)of $\geq 5 \mathrm{~mm}$, clinical attachment loss (CAL) $\geq 3$ and $4 \mathrm{~mm}$, and radiographic evidence of bone loss extending to at least one-third of the root length.

- Subjects who had never smoked.

\section{Exclusion Criteria}

- Subjects having undergone any form of periodontal therapy in the previous 12 months.

- Antibiotic and/or anti-inflammatory drug intake in past 3 months.

- Pregnant women and lactating mothers.

- Systemically compromised subjects.

- Patient with chronic liver diseases, nephrotic syndrome, diabetes, pancreatitis and rheumatoid arthritiss.

\section{Intraexaminer Calibration}

Intraexaminer calibration was achieved by the examination of 10 patients at a gap of one day, prior to beginning of the study. Calibration was regarded to be acceptable if both measurements were analogous to each other, up to $1 \mathrm{~mm}$ at the $95 \%$ level.

\section{Clinical Parameters}

The clinical parameters recorded at baseline and 30 and 90 days after treatment included various indices, such as plaque index, ${ }^{18}$ gingival index ${ }_{1}^{19}$ sulcus bleeding index, ${ }^{20}$ probing pocket depth and relative attachment level (RAL).

An acrylic occlusal stent was customized for each patient to fit it over the selected sites. Clinical measurements were done by using a straight periodontal probe (University of North Carolina, UNC-15) and using the groove as a guiding path. All measurement were rounded to the nearest millimeter $(\mathrm{mm})$. All the stents were preserved on the study casts to minimize distortion.

Pocket depths were measured from the gingival margin to the depth of the pocket. The relative attachment level (RAL) was measured as the distance from apical end of stent to the base of the periodontal pocket. 
For each participating subject, two nonadjacent sites were included if probing depth $\geq 5 \mathrm{~mm}$ were recorded and exhibited bleeding on probing in symmetric quadrants even after 14 days of completion of full mouth scaling and root planing. Randomization was carried out by flip of a coin and sites were divided into two groups as follows:

- Test group: Tetracycline fibers (Periodontal Plus $A B^{\circledR}$ ) were inserted into the periodontal pocket till resistance was experienced $\mathrm{Coe} \mathrm{Pak}^{\circledR}$ was used to seal the pocket orifice for 10 days.

- Control group: The pocket orifice was sealed with Coe pak $^{\circledR}$ for 10 days. Coe Pak ${ }^{\circledR}$ was removed subsequently and oral hygiene reinforcement of all participants was done.

Clinical parameters were re-recorded at both control and test sites after 30 days ( 1 month) and 90 days (3 months), after local drug delivery.

\section{Gingival Crevicular Fluid Sampling}

Gingival crevicular fluid collection was done at baseline, but one day prior to recording of clinical parameters to prevent contamination with gingival crevicular blood.

Test and control sites were dried and cotton rolls were used for isolation, prior to GCF sampling. A volume of $1 \mu \mathrm{l}$ of GCF was collected from each of the 60 sites (both test and control) by means of color-coded microcapillary pipettes (with a calibrated volume of 1-5 $\mu$ l) with an extracrevicular (unstimulated) method. Levels of $\alpha 2 \mathrm{M}$ in GCF samples were assayed by a specific ELISA kit (SIGMA, USA).

Gingival crevicular fluid sampling and assay at both test and control sites were repeated at 90 days after local drug delivery. Gingival crevicular fluid samples were again collected prior to clinical parameter recording.

\section{STATISTICAL ANALYSIS}

Changes in various clinical parameters at baseline to 90 days after local drug delivery therapy were analyzed by paired t-test (intragroup). Intergroup (test and control), comparisons of post-treatment changes were assessed by unpaired t-test. Friedman-Wilcoxon test was used for within group changes $p<0.05$ was considered as significant difference.

\section{RESULTS}

In 30 patients, after full mouth scaling and root planing, 60 sites were randomly selected, out of which 30 sites were test (experimental) which received tetracycline drug locally, and 30 sites were control sites which were not subjected to local drug delivery.

All the sites healed uneventfully with no complications or allergic reactions in relation to the local drug delivery. In our study, there was statistically significant reduction in all recorded clinical indices; and statistically significant gain was seen in relative attachment in both the control and experimental groups from the baseline (Tables 1 to 5 ).

Alpha-2-macroglobulin levels showed significant changes during the course of treatment. The levels of $\alpha 2 \mathrm{M}$ showed significant decrease after treatment in control sites (SRP) and experimental sites (tetracycline local drug delivery), $(\mathrm{p}<0.001)$. The comparison between the control site and experimental site, however, revealed no significant difference in the $\alpha 2 \mathrm{M}$ level (Table 6).

\section{DISCUSSION}

The study objective of the present randomized splitmouth clinical trial was to analyze the effect of conventional scaling and root planing (SRP) with local drug delivery of tetracycline fibers on clinical parameters to assess their impact on periodontal health and also on activity of $\alpha 2 \mathrm{M}$ levels in the GCF.

Both treatment modalities showed improvement of clinical parameters from baseline which was in accordance with the other studies. ${ }^{21}$

Table 1: Plaque index

\begin{tabular}{|c|c|c|c|c|c|c|}
\hline \multirow[b]{2}{*}{ Interval } & \multicolumn{3}{|c|}{ Control (SRP) } & \multicolumn{3}{|c|}{ Experimental (SRP and tetracycline) } \\
\hline & Mean $\mathrm{Pl} \pm S D$ & $t$-value & $p$-value & Mean $P I \pm S D$ & $t$-value & $p$-value \\
\hline 0 day & $2.680 \pm 0.3529$ & & & $2.729 \pm 0.3892$ & & \\
\hline 30 days & $1.546 \pm 0.3954$ & 14.681 & 0.0001 & $1.460 \pm 0.3067$ & 15.019 & 0.000 \\
\hline 90 days & $1.291 \pm 0.3193$ & 18.577 & 0.000 & $1.012 \pm 0.3134$ & 18.053 & 0.000 \\
\hline
\end{tabular}

PI: Plaque index

Table 2: Gingival index

\begin{tabular}{|c|c|c|c|c|c|c|}
\hline \multirow[b]{2}{*}{ Interval } & \multicolumn{3}{|c|}{ Control (SRP) } & \multicolumn{3}{|c|}{ Experimental (SRP and tetracycline) } \\
\hline & Mean $\mathrm{GI} \pm S D$ & $t$-value & $p$-value & Mean $G I \pm S D$ & $t$-value & $p$-value \\
\hline 0 day & $2.426 \pm 0.3340$ & & & $2.501 \pm 0.3266$ & & \\
\hline 30 days & $1.835 \pm 0.2746$ & 10.849 & 0.0001 & $1.564 \pm 0.3368$ & 12.645 & 0.000 \\
\hline 90 days & $1.447 \pm 0.2072$ & 17.640 & 0.000 & $0.7843 \pm 0.4298$ & 18.754 & 0.000 \\
\hline
\end{tabular}

Gl: Gingival index 
Alpha-2-Macroglobulin Levels in Gingival Crevicular Fluid Pre- and Post-scaling and Root Planing

Table 3: Sulcular bleeding index

\begin{tabular}{|c|c|c|c|c|c|c|}
\hline \multirow[b]{2}{*}{ Interval } & \multicolumn{3}{|c|}{ Control (SRP) } & \multicolumn{3}{|c|}{ Experimental (SRP and tetracycline) } \\
\hline & Mean $S B I \pm S D$ & $t$-value & $p$-value & Mean $S B I \pm S D$ & $t$-value & $p$-value \\
\hline 0 day & $2.908 \pm 0.4801$ & & & $2.833 \pm 0.3457$ & & \\
\hline 30 days & $1.850 \pm 0.4671$ & 14.578 & 0.0001 & $1.233 \pm 0.3212$ & 22.75 & 0.000 \\
\hline 90 days & $1.50 \pm 0.4101$ & 19.87 & 0.000 & $0.68 \pm 0.256$ & 29.10 & 0.000 \\
\hline
\end{tabular}

SBI: Sulcular bleeding index

Table 4: Probing pocket depth

\begin{tabular}{|c|c|c|c|c|c|c|}
\hline \multirow[b]{2}{*}{ Interval } & \multicolumn{3}{|c|}{ Control (SRP) } & \multicolumn{3}{|c|}{ Experimental (SRP and tetracycline) } \\
\hline & Mean $P P D \pm S D$ & $t$-value & $p$-value & Mean $P P D \pm S D$ & $t$-value & $p$-value \\
\hline 0 day & $5.48 \pm 0.634$ & & & $5.59 \pm 0.551$ & & \\
\hline 30 days & $4.53 \pm 0.588$ & 14.618 & 0.0001 & $3.70 \pm 0.459$ & 13.217 & 0.000 \\
\hline 90 days & $3.87 \pm 0.521$ & 18.227 & 0.000 & $3.16 \pm 0.534$ & 14.632 & 0.000 \\
\hline
\end{tabular}

PPD: Probing pocket depth

Table 5: Relative attachment level

\begin{tabular}{|c|c|c|c|c|c|c|}
\hline \multirow[b]{2}{*}{ Interval } & \multicolumn{3}{|c|}{ Control (SRP) } & \multicolumn{3}{|c|}{ Experimental (SRP and tetracycline) } \\
\hline & Mean $R A L \pm S D$ & $t$-value & $p$-value & Mean $R A L \pm S D$ & $t$-value & $p$-value \\
\hline 0 day & $8.40 \pm 0.556$ & & & $8.27 \pm 0.542$ & & \\
\hline 30 days & $7.33 \pm 0.641$ & NA & NA & $6.94 \pm 1.226$ & 8.974 & 0.000 \\
\hline 90 days & $6.78 \pm 0.595$ & 18.681 & 0.000 & $5.97 \pm 1.643$ & 10.867 & 0.000 \\
\hline
\end{tabular}

RAL: Relative attachment level

Table 6: Levels of alpha-2 globulin

\begin{tabular}{lllllll}
\hline & \multicolumn{2}{c}{ Control $(S R P)$} & & \multicolumn{3}{c}{ Experimental (SRP and tetracycline) } \\
\cline { 2 - 3 } Interval & Mean $\pm S D$ & Median & & Mean GI $\pm S D$ & Median & U test \\
\hline O day & $59.43 \pm 63.49$ & 45.35 & & $78.43 \pm 45.72$ & 60.32 & NS \\
90 days & $19.68 \pm 21.65$ & 16.21 & & $27.53 \pm 30.46$ & 20.27 & NS
\end{tabular}

NS: Not significant

Scaling and root planing alone cannot completely eradicate disease ${ }^{22}$ because of deficient accessibility to deep pockets, complex anatomical attributes ${ }^{23}$ bacteria invading into deep pockets, ${ }^{24}$ compilation of bacterial assemblies in dentinal tubules post scaling ${ }^{23}$ and frequent mechanical trauma inflicted onto the root which may result in diminished cementum thickness. ${ }^{25}$

Systemic and local antimicrobial agents are used along with scaling and root planing as an adjunct. Systemic use of antibiotics are associated with side effects, whereas mouth rinses and subgingival irrigation have an inherent limitation as drugs fail to reach the site of action in required concentrations. ${ }^{4}$ Technological advances in local delivery had lead to controlled release of drugs, thereby allowing effective drug concentrations at low dosage to be achieved in periodontal pockets.

Gingival crevicular fluid concentration of tetracycline in the average range of $1500 \mu \mathrm{g} / \mathrm{ml}$ is observed with Periodontal Plus $\mathrm{AB}^{\circledR}$ treatment, with the release concentration being almost linear for 10 days, as reported by trials undertaken to test their efficacy. ${ }^{22,26}$ Reported gain in relative attachment levels with tetracycline was more pronounced and has been attributed to longer period of delivery. Tetracyline fibers have also found to have a contributory anti-inflammatory effect due to substantivity, leading to attenuation of bone resorption. These fibers are credited with modulation and promotion of fibroblast attachment to root surfaces ${ }^{27}$ and collagenase inhibition. ${ }^{28}$ Remineralization of alveolar bone may be ascribed to infection control by tetracycline..$^{29-33}$

Condacci et $\mathrm{al}^{12}$ first reported the proteinase inhibitor role of $\alpha 2 \mathrm{M}$ in a periodontitis study, with significant reduction in the levels of $\alpha 2 \mathrm{M}$ after periodontal treatment. So far, there are no reported studies which have been conducted on $\alpha 2 \mathrm{M}$ with locally delivered tetracycline for treatment of periodontitis. In the current study, levels of $\alpha 2 \mathrm{M}$ were significantly reduced after treatment of patients with scaling and root planing (SRP) alone and also in experimental sites with adjuvant use of local tetracycline. The results of present study are supported by other reported studies. ${ }^{2,12,30}$

The current study observation suggests that $\alpha 2 \mathrm{M}$ is a relevant marker for follow-up of the treatment of periodontitis. A study by Junker et $\mathrm{al}^{31}$ revealed that $\alpha 2 \mathrm{M}$ levels in GCF and plasma showed no association, therefore, suggesting that this proteinase inhibitor is produced locally by fibroblast in the gingiva, which may be provoked by inflammatory cytokines, resulting in an increase in $\alpha 2 \mathrm{M}$ receptor expression in the local tissue. 


\section{CONCLUSION}

The present study revealed the following:

- Local drug delivery of tetracycline fibers along with scaling and root planing is an efficacious treatment modality in managing patients of moderate chronic periodontitis.

- Quantitative levels of $\alpha 2 \mathrm{M}$ in GCF is a suitable marker for follow-up of the treatment of periodontitis, however, further clinical trials with longitudinal observations are warranted to further evaluate its diagnostic and prognostic role.

\section{REFERENCES}

1. Van Dyke TE, Serhan CN. Resolution of inflammation: a new paradigm for the pathogenesis of periodontal diseases. J Dent Res 2003;82:82-90.

2. Adonogianaki E, Mooney J, Kinane D. The ability of gingival crevicular fluid acute phase proteins to distinguish healthy, gingivitis and periodontitis sites. J Clin Periodontol 1992;19:98-102.

3. Zasloff M. Innate immunity, antimicrobial peptides, and protection of the oral cavity. Lancet 2002;360:1116-1117.

4. Lamster IB. Evaluation of components of gingival crevicular fluid as diagnostic tests. Ann Periodontol 1997;2:123-137.

5. Sandholm L. Proteases and their inhibitors in chronic inflammatory periodontal disease. J Clin Periodontol 1986; 13:19-26.

6. Travis J, Salvesen GS. Human plasma proteinase inhibitors. Annu Rev Biochem 1983;52:655-709.

7. Chen HY, Cox SW, Eley BM. Cathepsin B, alpha-2-macroglobulin and cystatin levels in gingival crevicular fluid from chronic periodontitis patients. J Clin Periodontol 1998;25:34-41.

8. Nagase H, Itoh Y, Binner S. Interaction of alpha-2-macroglobulin with matrix metalloproteinases and its use for identification of their active forms. Ann N Y Acad Sci 1994;732:294-302.

9. Knöfler G, Purschwitz R, Jentsch H, Birkenmeier G, Schmidt H. Gingival crevicular fluid levels of aspartate aminotransferase and alpha-2-macroglobulin before and after topical application of metronidazole or scaling and root planning. Quintessence Int 2008;39(5):381-389.

10. Schenkein HA, Genco RJ. Gingival fluid and serum in periodontal diseases I, Quantitative study of immunoglobulins, complement components, and other plasma proteins. J Periodontol 1977;48:772-777.

11. Sottrup-Jensen L. Alpha-macroglobulins: structure, shape and mechanism of proteinase complex formation. J Biol Chem 1989;264:11539-11542.

12. Condacci L, Cimasoni G, Ahmad-Zadeh C. Alpha-2macroglobulin in sulci from healthy and inflamed human gingivae. Infection and immunity 1982;36:66-71.

13. Sengupta S, Lamster 1B, Khocht A, Duffy TA, Gordon JM. The effect of treatment on IgG, IgA, IgM and (alpha-2macroglobulin in gingival Crevicular fluid from patients with chronic adult periodontitis. Arch Oral Bio 1988;33:425-431.

14. Condacci I, Cimasoni, G, Rey M, Baehni P. In vitro synthesis of alpha-2-macroglobulin by human gingival fibroblasts. Arch Oral Bio 1988;33:407-412.

15. Giannopoulou C, Di Felice R, Andersen E, Cimasoni G. Synthesis of alpha-2-macroglobulin in human gingiva: a study of the concentration of macroglobulin and albumin in gingival fluid and serum. Arch Oral Bio 1990;35:13-16.
16. Rosin M, Benjamin P, Rogers $\mathrm{P}$, Gibson M, Van Leuven $\mathrm{F}$, Johnson W, Curtis M. Elevated conversion of alpha-2macroglobulin to the complexed form in gingival crevicular fluid from adult periodontitis patients. J Periodontol 1995;30:436-444.

17. 1999 International Workshop for a Classification of Periodontal Diseases and Conditions. Papers. Oak Brook, Illinois, October 30-November 2, 1999. Ann Periodontol 1999;32-37.

18. Turesky S, Gilmore ND, Glickman I. Reduced plaque formation by the chloromethyl analogue of vitamin C. J Periodontol 1970;41:41-43.

19. Loe H, Silness J. Periodontal disease in pregnancy. Acta Odontol Scand 1963;21:533-542.

20. Muhlemann HR, Son S. Gingival sulcus bleeding: a leading symptom in initial gingivitis. Helev Odontol Acta 1971;15: 107-113.

21. Badersten A, Nilveus R, Egelberg J. Effect of nonsurgical periodontal therapy (VIII). Probing attachment changes related to clinical characteristics. J Clin Periodontol 1987;14:425-432.

22. Aimetti M, Romano F, Torta I, Cirillo D, Caposio P, Romagnoli R. Debridement and local application of tetracycline-loaded fibres in the management of persistent periodontitis: results after 12 months. J Clin Periodontol 2004;31:166-172.

23. Radvar M, Pourtaghi N, Kinane DF. Comparison of 3 periodontal local antibiotic therapies in persistent periodontal pockets. J Periodontol 1996;67:860-865.

24. Saglie R, Newman MG, Carranza FA Jr, Pattison GL. Bacterial invasion of gingiva in advanced periodontitis in humans. J Periodontol 1982;53:217-222.

25. Lie T, Bruun G, Boe OE. Effects of topical metronidazole and tetracycline in treatment of adult periodontitis. J Periodontol 1998;69:819-827.

26. Heijl L, Dahlen G, Sundin Y, Wenander A, Goodson JM. A 4-quadrant comparative study of periodontal treatment using tetracycline containing drug delivery fibers and scaling. J Clin Periodontol 1991;18:111-116.

27. Seymour RA, Heasman PA. Tetracyclines in the management of periodontal diseases: a review. J Clin Periodontol 1995;22: 22-35.

28. Steinberg D, Friedman M, Soskolne A, Sela MN. A new degradable controlled release device for treatment of periodontal disease: in vitro release study. J Periodontol 1990; 61:393-398.

29. Patianna GP, Valente NA. The adjunctive use of locally delivered tetracyclines in periodontal therapy: a narrative review of the recent literature. Int Dent Med J Adv Res 2015;1:1-4.

30. Plagnat D, Giannopoulou C, Carrel A, Bernard JP, Mombelli A, Belser UC. Elastase, alpha-2-macroglobulin and alkaline phosphatase in crevicular fluid from implants with and without periimplantitits. Clin Oral Implants Res 2002; 13:227-233.

31. Junker A, Schmidt H, Birkenmeier G. Analyse von alpha2-macroglobulin in gesunder gingiva und bei parodontitis. Dtsch Zahnärztl Z 2000;55:497-501.

32. Mehta A. Risk factors associated with periodontal diseases and their clinical considerations. Int J Contemp Dent Med Rev 2015; 2015: Article ID: 040115. DOI: 10.15713/ins.ijcdmr.31

33. Nandini TKS, Mahantesha R, Mani K, Kranti. 'Pharmacological agents for periodontal regeneration: a review.' Int J Contemp Dent Med Rev 2015; 2015: Article ID: 120115. DOI: 10.15713/ ins.ijcdmr.35. 